\title{
Rovena Troqe \\ On the concept of translation: A perspective based on Greimassian semiotics
}

\begin{abstract}
This article outlines some representative epistemological attitudes in translation studies and presents a model for defining translation. Basing our reflection on the work of translation scholars, we identify approaches that avoid the problem and others that claim to deal with it but fail to do so. The article is guided by the following questions: Is there a need to define the object of study when studying translation? If so, what are the origins and consequences of such a definition? How might this affect certain beliefs in the translation theories? Drawing on a Greimassian semiotic approach, we present a new model for defining the concept of Translation.
\end{abstract}

Keywords: translation studies, Greimassian semiotics, epistemology, concept of translation, semiotic square, metatheoretical model of translation

DOI 10.1515/sem-2014-0045

\section{Premise}

The evolution of translation studies epistemology is characterized by the recurrence of dyadic concepts called by Andrew Chesterman (1997) the "supermemes" of translation. Found in the main studies on translation, these are enduring ideas with a high level of generalization, e.g., "equivalence," "untranslatability," "all-writing-is-translating," and oppositions such as "free versus literal translation" and "source versus target text." Other paired concepts can also be added to these supermemes, e.g., meaning versus form, ethnocentric versus ethnic translation, recreation versus reproduction, original versus copy, otherness versus identity, and difference versus equivalence.

The nature of the epistemic modalities used to understand the ways of thinking about and doing translation is also dualistic and cyclical. Considerations of translation have historically focused on two antithetical methods applied to the translation of two main text-typologies: literary and religious texts (St. Jerome

Rovena Troqe: University of Geneva. E-mail: rovena.troqe@unige.ch 
1976 [390]; Luther 2002 [1530]; Schleiermacher 1997 [1813]), or, according to certain scholars, literary or technical texts (Folkart 1984; Reiss 1971, 2000).

A first step towards theoretical unification was made in 1972, when James S. Holmes (2000 [1972]) proposed a taxonomy of research areas pertaining to a self-defined discipline: that of translation studies, a theory aiming at describing the practice and developing explanatory and predictive models. Classification of subject area is based on an initial major subdivision into two main branches: a pure theory (pure translation studies) and an applied theory (applied translation studies; Holmes 2000 [1972]: 172).

As Ubaldo Stecconi (2004: 472-473) notes, throughout history, issues related to applied and descriptive theory have been developed through several contributions from different disciplinary fields. These contributions shed light onto important translational problems i.e., cultural, communicative, socio-economic, political, ideological, ethical, poetic, and functional features of translation. All in all, these studies raise awareness about the different facets of translation, a discipline that has acquired a transcultural and interdisciplinary dimension. However, focusing on each of these aspects fosters some degree of dispersion of the theory, which might be understandable, since translation is by its very nature a multi-criteria phenomenon, but might also be detrimental, should it lead to theoretical positions denying the unity and autonomy of the discipline.

Indeed, the tendency towards fragmentation fosters, in certain circumstances, a sort of resistance to developing a unified field of study constituting a discipline in conventional terms. According to Antoine Berman (1989) there are so many heterogeneous linguistic, ethical, poetic, cultural and even religious implications that one cannot think about translation studies as a self-governing science. The area of translation cannot represent a "field" in the proper scientific sense and might only be an actual theory if it focuses on the horizon of meaning restitution. Restitution of meaning is the only point common to all translations, but is also the most problematic because it conceals work on "form," on the signifier ("le travail sur la lettre"). The work on the formal level plays an ethical, poetic, cultural, and religious role in the history of mankind (Berman 1989: 676). According to this perspective, translation studies can exist only as a "reflection" on translational experiences. Reflection helps restore the meaning of form but it cannot pretend to describe, analyze and regulate the practice because it is always linked to geographical areas, to specific areas of language traditions and culture. The concept of translation is subject to divisions due to variations in time, culture, and society; therefore, translation studies are strongly influenced by epistemic differences and scientific relativity. The ontological relativism that characterizes Berman's epistemological attitude echoes empirical conventionalism and language indeterminacy. Berman associates respect to form to the criticism of 
cultural ethnocentrism and relativity of deterministic models. This position rises against unilateral and universal ideas of translation and promotes scepticism of the possibility of theoretical generalization.

Jean-René Ladmiral (2003) proposes to define the epistemological discourse on translation by constructing a thematic classification of the four types of historical studies. "Translation before yesterday" (traductologie d'avant-hier) refers to the prescriptive, philosophical and literary, pre-linguistic school; "translation yesterday" (traductologie d'hier) is linguistics applied to the translation school; "translation today" (traductologie d'aujourd'hui) refers to productive and inductive theories attempting to develop a scientific approach to translation in order to anticipate difficulties in the practice - today, translation studies are a sort of "praxeology" (Handlungswissenschaft) aimed at responding to a "social demand" (Ladmiral 2003: 149). Finally, Ladmiral (2003: 161) foresees the establishment of a fourth component, the "translation of tomorrow" (traduction de demain), based on the cognitive sciences, which would be an inductive and scientific study focused on the process of translation, on what happens in the translator's "black box." Ladmiral does not inquire the concept of "black box," nor does he give a definition of it, but he foresees a very near future where translation and semiotic scholars address the question. In fact, shortly after Ladmiral's forecast, this metaphor was inquired by Dinda Gorlée (2010), who stated that "the black box deserves, however, a deeper study outside being merely 'an Unknowable Knowable' (CP 6.492)" (2010: 84). Starting from the discussion of different "black box" theories (i.e., behaviorism in Friedeberg and Silverman, Grime's considerations on machine translation, the structuralist approach of Fauconnier and Turner, developmental psychology in Vygotsky and Piaget, behavioral semiotics in Morris and philosophy and cognition in Hamlyn) Gorlée articulated the concept "through the ancient formula aliquid stat pro aliquo, updated by Peirce's semiotics and then modernized” (Gorlée 2010: 91).

Moreover, Ladmiral's “psychologizing” approach to translation is aimed at allowing translators to reflect on their own practice in order to increase their know-how, by optimizing their efforts and collecting good translational solutions. And here, too, Ladmiral is drawing close to Gorlée's idea of knowledge as conceived by Peirce: "For Peirce, reasoning - including after meditation, interpretation, and translation - is an experience of outward talk which stays 'embodied in talk with oneself,' while for him inward talk is 'mediation, consideration, and thought”" (Gorlée 2010: 92).

Beyond the interesting parallels that may be drawn between Ladmiral and Gorlée's Peircean semiotics, we consider - despite the article's promising title ("Epistemologie de la traduction") - that Ladmiral clearly decided to set his discussion along historical lines rather than in the epistemological domain, 
because his evolutionary view of the types of theories is a sort of phenomenological classification (étiquetage phénoménologique) of the various contributions in translation studies. It is indeed unusual to base an epistemological perspective on a so-called "crumbled theory" (théories en miettes), a sort of "magic box" of translators" best solutions. According to this perspective, translation theory does not arise as a unitary construction but as a set of plural theoretical items, a set of "theorems," of elements of a theory that should function as a toolbox from which translators can draw conceptual tools at their convenience (Ladmiral 2003: 161).

Many translation scholars have often adopted, whether intentionally or spontaneously, a relativistic and naturalizing perspective based on the human subject, the indeterminacy of meaning and therefore on the indeterminacy of translation. This theoretical position is based on the gnoseological conviction that human knowledge is limited because of its physical and psychological nature - linguistic and cultural differences lead to fundamental differences in cognitive patterns. Thus, translation has to do with the way one positions oneself in relation to the other. It involves imposing schemes that postulate the world in specific, linguistic, cultural and social terms. Translation is thus a practice that attempts (more or less successfully) to realize in practice what theory denies, namely, to reduce the irreducible differences in conceptual representations of reality.

Within a fragmented and often disavowed theoretical framework, a new perspective has been proposed by Chesterman (2006) based on Popperian philosophy. The necessary and sufficient conditions to speak about the discipline and the concept of Translation are: the identifying criteria in order to define its object of study and methodological guidelines, and determining its purpose and motivation. The Popperian approach thus allows problems to be regrouped, solutions to be proposed by advancing research hypotheses, and eventually for these hypotheses to be verified and adjusted by means of practical applications. A theory develops, improves, from hypotheses that are first invented then justified, tested and adjusted if necessary, or rejected because science advances beyond problems and questions (Chesterman 2006: 172-173). According to Chesterman, translation studies must determine coherent and consistent groups of hypotheses. These hypotheses should be of an interpretive nature (define the object of study), of a descriptive nature (describe translated texts and the communicational context), of an explanatory nature (translational causes and effects), and predicative (anticipate problems and propose solutions). On one hand, Chesterman's epistemological proposition and methodological procedure on how to define the object of study signify an important landmark, at a time when theoretical thinking is often intuitive and erratic. On the other, Chesterman re-opens the 
debate on the epistemological question first addressed by Holmes when he proposes selection criteria of core problems and methodological pathways, thus ensuring an assessment for probable solutions. Following his Popperian methodological approach, we will focus (in section 3) on what Chesterman calls the "interpretive hypothesis," a hypothesis addressing definitional questions in Translation Studies. In this paper, we will actually give a new definition of the concept of Translation and therefore base our reasoning on an abductive inference, "thus: it is hypothesized that if $\mathrm{X}$ is interpreted as $\mathrm{Y}$, added value will ensue" (Chesterman 2008: 54).

\section{The interpretative semiotics models of translation}

Semiotic contributions to translation studies represent a valid attempt to define the nature of the concept of translation as a specific object of study. Semiotic approaches are all based on Peirce's semiotics and on his general principle that semiosis, i.e., production of meaning, is translation (Gorlée 1994: 153). With this theoretical background, different authors, semioticians and translation scholars have provided descriptive models of the concept of translation. Amid these models, the most relevant to our new theoretical proposal are those by Dinda Gorlée (1989, 1994, 2004), Cécile Cosculluela (1996, 2003), Ubaldo Stecconi (2004), Susan Petrilli (2000, 2001, 2002) and Siri Nergaard (2001).

Before discussing these authors' contributions to translation studies, we will make a brief reference to Roman Jakobson, the first linguist to associate semiotics with the study of language. Beyond his famous typology of translations (Jakobson 2004 [1959]), Jakobson's novelty lies in the association of Peirce's theory of sign with the study of language and translation. Dealing with the issue of poetics, Jakobson states that "many poetic features belong not only to the science of language but to the theory of sign, that is, to general semiotics" (Jakobson 1960: 351). In "On linguistic aspects of translation," he stresses the fact that the meaning of a word is a general semiotic entity before being a specific linguistic one. In a broader perspective, "the meaning of any linguistic sign is its translation into some further, alternative sign, especially a sign "in which it is more fully developed," as Peirce, the deepest inquirer into the essence of signs, insistently stated" (Jakobson 2004 [1959]).

Opening a real new dimension in pure translation theory, Dinda Gorlée's kaleidoscopic work set a seminal precedent in the study of translation "assimilated to semiosis, or sign activity, in Peirce's sense of this concept," and inquired 
through "intellectual experiments, abstract thought-signs ... (that) do not pretend to solve practical problems" (Gorlée 1994: 10).

Gorlée's research has the merit to have overcome the empirical "parasitism" originating from the linguistic approach to translated (literary) texts; she has indeed set the study of translation in a more complex and multidimensional semiotic paradigm. From a Peircean semiotics viewpoint the "meaning of a sign is its translation into another equivalent or perhaps more developed sign" (Peirce in Gorlée 1994: 27), which means that translation, seen as a sign-action, is not a fixed event or product, rather, it is a movement of expansion, of continual interaction of change and growth (Gorlée 1994: 231). This point has consequences for another feature of Gorlée's theory - the concept of "equivalence," a topic of extreme interest to us. In fact, each sign-movement directed at seizing meaning implies a change in the seizing sign. Therefore, it is logically impossible to conceive equivalence without the concepts of "otherness," "meaning growth," and "difference." "Equivalence, in the strictest sense, between sign and interpretant is therefore logically impossible: it would stifle the growth of knowledge, which growth is exactly the point of sign production and sign use" (Gorlée 1994: 181).

Gorlée insists on the counterintuitive attitude widespread in translation studies that consists in reducing translational semiosis to mimesis, or to a mirroring procedure in order to realize a kind of "equivalence.” Equivalence intended in the sense of a relation of correspondence between two interchangeable realities (original and translated text) is, in the semiosic standpoint, a misconception, since translation is actually "concerned with, namely the sign-and-codeenriching confrontation between sameness and otherness” (Gorlée 1994: 171). The recognition of the fact that translation is the semiotic relation between sameness and otherness is the starting point for presenting a new Greimassian perspective on the concept of Translation.

In her research, Cosculluela (1996, 2003) acknowledges the work of Dinda Gorlée (1994), the first author to directly link Peircean semiotics to translation studies in a new research field defined as "semiotranslation." Basing her work on a mainly diachronic analysis, Cosculluela examines the historical progression in translation studies and shows that it has evolved from a binary to a dialectical stage. The discourse on translation unfolded from a dyadic to a triadic form, Secondness to Thirdness, as per Peirce's phaneroscopic categories. Following the triadic logic, Cosculluela proposes to define translation as a phenomenon that is of the same nature as the sign - it is the synthesis of a representamen which stands in place of an object for an interpretant - which functions as a representamen for another interpretation, in a sliding and unlimited way. Object, source text, and target text represent three constituting elements of the concept of translation (Cosculluela 2003: 123). In Peircean terms, translation occurs as Firstness 
- the simple possibility of being, as Secondness - being in relation to another, the dyadic way of being, and as Thirdness - linking to Firstness and Secondness in order to produce meaning. According to this perspective, the translator has a fundamental role because it is through him/her that the source sign is transformed into a target sign. In this process, the translator becomes an Interpreter, ${ }^{1}$ interpreting the text (comprehension phase), a Muser, letting the meaning of the text reveal its nature beyond its materialization and a graphic designer, because he rematerializes the original meaning in a translated representamen, which stands for the original representamen and arouses the same interpretants (Cosculluela 2003: 119).

Apart from proposing an interesting new way to semiotically re-examine previous methods of translation, such as Vinay and Darbelnet's method and Lederer's deverbalization theory, Cosculluela emphasizes the interpretive nature of translation, seen as a generative process that increases meaning. In order to be understood, each sign must be translated. Understanding then occurs through and into another sign more developed than the sign it is interpreting. "But a sign is not a sign unless it translates itself into another sign in which it is more fully developed. Thought requires achievement for its own development and without this development it is nothing. Thought must live and grow in incessant new and higher translations, or it proves itself not to be genuine thought" (CP 5.594).

Ubaldo Stecconi (2004, 2007, 2008) addresses definitional problems of a general nature, sets his research in the field of pure theoretical translation studies and aims at providing a general definition of the concept of translation by calling upon interpretative semiotics. Stecconi bases his approach on the Ch. S. Peirce's theory of signs and, drawing on an analysis and criticism of the semiotic works of Gorlée and Cosculluela, establishes the semiotic conditions to translation. Translation as T-semiosis should be conceived as a special form of semiosis and therefore as a triadic concept, constituted by three modes of being, interrelated in a trivalent way: "events" (Secondness) - textual products, "norms of translation" (Thirdness) - prescriptive rules on how to perform translation, and the theoretical "foundation" (Firstness) of translation (Stecconi 2004: 474-477). The foundation of translation is made up of three basic aspects (a one-two-three series, as Stecconi names them): "similarity," "difference," and "mediation." "Similarity" is not defined as an absolute, rather, it is culture and time-dependent. It must, however, be respected in order for translation to exist. "Difference" is the second condition and refers to the gap that has to exist between languages and cultures

1 In a similar way, these three stages are theorised by Danica Seleskovitch and Marianne Lederer, interpreters and teachers of the ESIT in Paris: understanding, deverbalization and re-expression. 
in order for translation to occur. "Mediation" refers to the fact that translation is something that happens when something or somebody speaks on behalf of something or somebody else.

Even if this model demands, in our opinion, further investigation some scholars (Hartama-Heinonen 2008: 173) question the pertinence of the affiliation of Stecconi's “triplet" to the Peircean semiotics perspective - but it is intriguing to note that in this model the concepts of "similarity"2 and "difference" are somehow brought together to describe what we consider to be the paradox of translation. Indeed, interpretative semiotics is the theoretical approach that has best revealed the paradoxical nature of translation until now.

This aspect is also put forward by Susan Petrilli (2000, 2001, 2002) and Siri Nergaard (2001). Both scholars highlight the idea that the original sign, even if it is the first sign, cannot stop the production of meaning in sign-translation. The second sign transcends and enriches the first sign and the process of semiosis is itself a sequence of signs and interpretants that follow each other in progressive development. "the text flourishes in its transmigrations from one text to another. This does not only happen among texts written in different languages, in translation, but also in the same language and in the same body of literature" (Petrilli 2002: 165).

Petrilli, in particular, stresses the idea that "alterity" develops before "similarity" and that both concepts coexist simultaneously. A translated text will never be completely equivalent to the original, or it would be a simple photocopy of it. "A translation must be at once similar and dissimilar. This is the paradox of translation, which is the same as that of the multiplicity. To admit the possibility of translation is to admit, contradicting oneself, that something may be at once similar and dissimilar" (Petrilli 2002: 156).

Siri Nergaard (2001) also shares this vision and claims that translation is a process that involves semiotic "sign-sliding." The interpretant of the translated text "drifts" the meaning of the original text and the relationship between the two texts is at once one of equivalence and of difference. The difference between original and translation is a necessary condition since without difference the translation would not grasp the meaning of the original.

2 The author states that only later did he deem it appropriate to use the word "similarity" instead of "equivalence." This is understandable from a historical perspective (the word equivalence is incredibly dense and complex - some consider it to be the "bête noire" of translation studies), but in the economy of Stecconi's theory, "similarity" might jeopardize the vague and indeterminate nature of basis since it occurs only in retrospect, after the analysis of translational events. In our opinion, it might be not wrong to say that there is "equivalence" in the foundation concept of translation and that there is similarity in the criticism of translation events. 
"Difference" and "equivalence" appear to be conditions intrinsic to translation. Equivalence appears in each era of translation studies history and there is no translation approach that could avoid dealing with it. Be it formal, dynamic, communicative, pragmatic, semantic, lexical or functional, the concept of "equivalence" constitutes the premise and consequence of any speculative study and any empirical act of translation. "Equivalence" has recently been adapted into the more compromising idea of "similarity" (Chesterman 1996; Hewson 2012), and this is related, in our opinion, to a rising belief that it is closely related to its opposite concept, “difference.”

The idea that translation has to do with "difference" is increasingly recurring, especially among semioticians who, by the very logic of semiosis as a dynamic and evolving meaning process, have laid down the antinomic basis underpinning translation. Several translation scholars have also stressed the need to introduce the idea of difference in the definition of translation. For instance, Jacques Derrida (1967) and Lawrence Venuti (2002) raised the question of change in the "verbal body" - sound and visual materiality - that takes place when the original text is translated into another language. Translation dismantles the context of the original text and creates a new verbal body. Translation inscribes linguistic and cultural differences that make the translated text an autonomous and independent entity. In this sense, the very question of the degree of similarity shows up when the translated text comes into being, and when it is "declared" to be an equivalent of the original text.

\section{A generative semiotic model of translation}

Following on from scholars who advocate developments in the pure and general theory of translation, we introduce the possibility of investigating the fundamental conditions of translation in the generative semiotics framework developed by Algirdas J. Greimas (Greimas 1970, 1983, 1987, 1990), more specifically by applying the semiotic square to the essential and intrinsic characteristics that constitute the concept of translation (Greimas and Courtés 1982 [1979], 1986).

Epistemologically, for any kind of object, generative semiotics conceives the generation of meaning as a trajectory evolving from virtual and simple $a b$ quo instances - abstract kernels of meaning as little defined as possible - that evolve into successive, increasingly refined ad quem significative articulations. Seen as a trajectory, rather than a production of utterances in discourse, meaning expands from deep and virtual levels into more developed and actualized elements of narration and eventually into the realized level of discourse manifestation. Greimas calls this non-linear and dynamic progression of meaning the "generative 
trajectory" (le parcours génératif du sens). Meaning is first located and organized into elementary and narrative structures ("immanent level") that precede its linguistic manifestation, its occurrence as utterances combined in discourse (“apparent level”).

The abstract and deep level of the generative trajectory - defined as the "elementary structure of signification" - represents the comprehensive and virtual mode of existence of any object of study. The visual representation of this structure is termed a "semiotic square." "By semiotic square is meant the visual representation of the logical articulation of any semantic category. The elementary structure of signification, when defined - in a first step - as a relation between at least two terms, rests only on a distinction of opposition which characterizes the pragmatic axis of language" (Greimas and Courtés 1982 [1979]: 308).

The semiotic square organizes taxonomic terms - units of meaning constituting the "fundamental semantics" - into syntactic oriented operations and relations that constitute the "fundamental syntax."

The semiotic square comprises sequences of logical relations and operations. Among these, the most important relation is the binary opposition between two primitive terms, $s 1$ and s2. ${ }^{3}$ These terms identify two minimal and opposite values belonging to the same category, defined as semantic axis $\mathrm{S}$. The binary opposition s1 versus s2 offers an enlargement to the simple binary logics, since S stands as a synthetic and complex category that encompasses and transcends the primitive originating terms. In the semantic axis, the two opposite positions are simultaneously assumed because s1 can only exist if it simultaneously refers and is opposed to s2, e.g., "white" simultaneously refers to "black," "male" simultaneously refers to "female," since "white" and "male" are internally defined by virtual opposition to their contrary poles, "black" and "female."

In order to explain the mechanism of the semiotic square, references are made to the veridictory modalities (modalitiés veridictoires) as defined in Semiotics and Language by Greimas and Courtés (1982 [1979]: 369).

In the veridictory square, the oppositional relation between the two terms, "being" and "seeming," constitutes the semantic axis of contraries in which "being” opposes and simultaneously implies "seeming." The semantic category that subsumes and specifies the two terms in a hyperonymic and hierarchical mode is called, in this case, "truth" (Figure 1). "Truth" is a value associated to anything that simultaneously "is" and "appears" to be true. In the semiotic

3 This discussion of the mechanisms of the semiotic square is based on Greimas's main works with special reference to Greimas and Courtés (1982 [1979], 1986). 


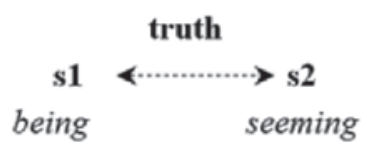

relation of contrariety between two primitive terms belonging to one semantic category operation of opposition axe of contraries

Fig. 1: Semiotic square of translation

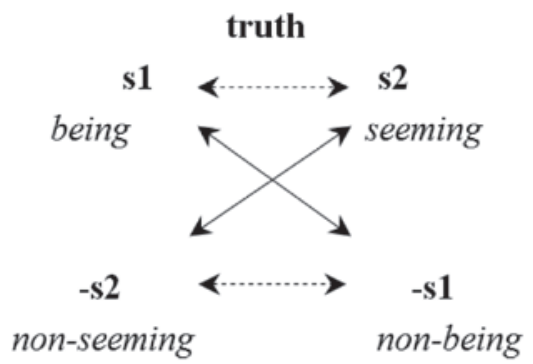

falseness

relations of contradiction derived from the negation of the two primitive terms operation of negation axis of contradictories

Fig. 2: Semiotic square of translation

square, the value "truth" represents a complex term, also called metaterm (Greimas and Courtés 1982 [1979]: 310).

Separately, these two positions generate their contradictory terms -s1 and -s2 (Figure 2). Each primitive term is not only defined by oppositional relationship s1 versus s2, but also by a relationship of contradiction that points to the impossibility of each term being present together with its negatives, i.e., s1 cannot be present with -s1 and, by the same token, s2 cannot be present together with -s2. From a dynamic perspective, the relationship of contradiction is an operation of negation performed on the two primitive terms (s1 and s2), which give rise to the two corresponding contradictories (-s1 and -s2). The contradictories are subsumed in sub-semantic neutral axis -S, which makes up for privation and negation and is opposed to the semantic axis S. 


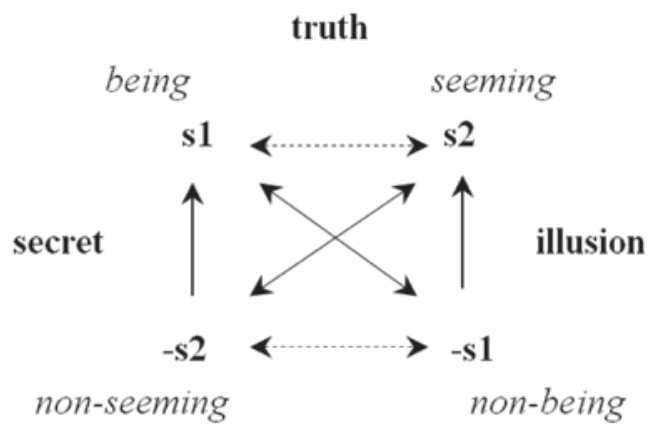

$$
\begin{gathered}
\text { falseness } \\
\text { relation of complementarity } \\
\text { operation of assertion }
\end{gathered}
$$

Fig. 3: Semiotic square of translation

In the veridictory modalities, the relationship of contradiction does not allow for co-existence between "being" and its negative and contradictory term "no-being," nor for a co-existence between "seeming" and its negative and contradictory term "not-seeming." Contradictories are encompassed in a sub-semantic axis, "falseness," which is opposed to the semantic axis "truth."

The operation of assertion, carried out on the contradictories, allows us to see if there is any implication between the contraries $\mathrm{s} 1 / \mathrm{s} 2$ axis and the contradictories -s1/-s2 axis (Figure 3). If the assertion of contradictories appears as an implication of primitive terms, i.e., when the term s1 is a presupposed term of contradictory term -s2 and when the term $\mathrm{s} 2$ is the presupposed term of the contradictory term - $\mathrm{s} 1$, then it can be said with certainty that the primitive terms $\mathrm{s} 1$ and s2 belong to one semantic category. The relationship between s1 and -s2, as well as between -s2 and s1, is called a relationship of complementarity, and the operation is a deixis; positive deixis (s1/-s2) and negative deixis (s2/-s1).

In the veridictory square, the operation of assertion of the contradictory terms allows us to establish the complementarity between the terms "non-being" and "seeming," since the assertion of the term "non-being" presupposes the complementary term "seeming." Analogously, carrying out an operation of assertion on the "non-seeming" implies the complementary term "being."

This operation allows for two more complex positions to be generated: the metaterm that subsumes s1 (being) and -s2 (non-seeming), i.e., "secret," and the metaterm that subsumes s2 (seeming) and -s1 (non-being), i.e., "illusion." 
In this veridiction square the seeming/non-seeming schema refers to the manifestation of an object, of an event, of an utterance, while the being/nonbeing schema refers to the immanence and deep meaning of an object, of an event, of an utterance. The veridictory square is a framework within which the manifestation of any object ("seeming" and "non-seeming") may lead to epistemic inferences concerning its immanence ("being and non-being"). The veridictory modalities therefore allows for statements concerning "the being of being."

The veridictory process that unveils immanence from manifestation is based on an important premise: it is based not on the "state of things" (Greimas and Courtés 1982 [1979]: 369), i.e., on the adequacy to an external referent, rather, it describes the simulacrum of truth represented by the writer (or enunciator) and the adhesion to this simulacrum by the reader (or enunciatee). A "veridiction contract" is established between the "make-believe" (persuasion) of the writer and the "true-believing" (interpretation) of the reader. Indiscriminately, all types of speech or text - whether literary, poetic, religious or scientific - build their own internal reference, portray a truthful reality. Therefore, according to the veridictory perspective, it is irrelevant whether a text or speech is true or likely to be true, since truth is an agreed value. This definitely explains veridiction as a variable evolving over time, places and culture.

Within this framework, translation - seen as a semiotic object - becomes a tangible sign of the shift in the veridictory dimension between two cultures and two periods of time. For instance, the veridiction contract established by Livius Andronicus and his Latin readers when he translated the Odyssey in the third century B.C. is not the same veridiction contract that Salvatore Quasimodo established with the readers of his translation of the same work in 1945.

The degree of veridiction of translated texts changes in time and translated text may appeal to all veridictory terms. A translated text may be generated in the metaterm "truth" when it "is" and simultaneously "seems to be" a translation (e.g., facing-page translations); it may appeal to the metaterm "secret" (being/ not-seeming) in the case of covert translations (translations that are not declared to be translations); or it may appeal to the metaterm "illusion" (seeming/nonbeing), on which most of the translated texts that appear to be original are based, but in fact are not.

Veridiction contracts change not only because the translator's attitude (poetics of translation and cultural reception of texts) towards the original text changes, but also because the epistemic and theoretical attitude towards the concept of translation in general (norms and translation criticism) changes as well. The poetics and epistemology of translation bring up the question of the 
generation of an individual identity (poetics of the translating subject) and a collective identity (cultural norms). Therefore, translation theory should not refrain from appraising the study of the conditions under which identity comes into being in a translated text, through the act of translation and through the modalities that establish its veridiction.

Veridictive modalities allow us to acknowledge when a semiotic object is true, false, secret or illusory but they do not say anything more about the object itself. Indeed, generative theory does not provide a solution for understanding the identity of a semiotic object in itself. Yet, reflecting on the categories that allow for something to be as an identity is crucial to the concept of translation, since translation always happens as a cross-cultural, cross-linguistic and interpersonal "identity-confrontation." The individual and cultural translating identity "Me" is generated and related to "non-Me," the category that refers to the author of the original text and the other culture and language. "Non-Me" constitutes an intrinsic condition, the surrounding space that motivates the generation and organization of "Me." Therefore, to translate means to accept, amend or reject "the external "non-Me," according to paradigms and methods that determine the meaning of "Me" in relation to "non-Me. To translate means to speak of "Me" with the pretext of "non-Me"; it is the act that establishes "Me" while simulating the other.

According to this perspective, identity is the category that completes discourse on the concept of translation and sets its logical and semiotic conditions, along with the veridictory modalities.

We therefore propose to apply the semiotic square to the study of the category of identity. We define "identity" as a set of characteristics that allows a subject, an object or an event to be "different" and "equivalent" in relation to another subject, object or event. "Difference" refers to the rule of contrast and opposition that allows the emergence of an autonomous and unique identity. Translation primarily exists as a different form of expression, as a body that differs from the original text. Identity is therefore primarily constituted as differentiation. According to the semiotic square, in order to be, the first primitive term must refer to and imply its opposite: "difference” implies "equivalence."

"Equivalence" refers to the rule of derivation, the possibility, the necessity that an identity emerges by drawing, copying or simulating something else. In translation, equivalence is guaranteed by the persistence of a deep substance of contents.

The two opposite terms, "equivalence" and "difference" are simultaneously assumed by the hyperonimic and hierarchical term identity, i.e., to the emergence of the identity "Me." Therefore, the metaterm "Me" is simultaneously different and equivalent in relation to its opposite metaterm "non-Me." 


\section{Semiotic square of identity}

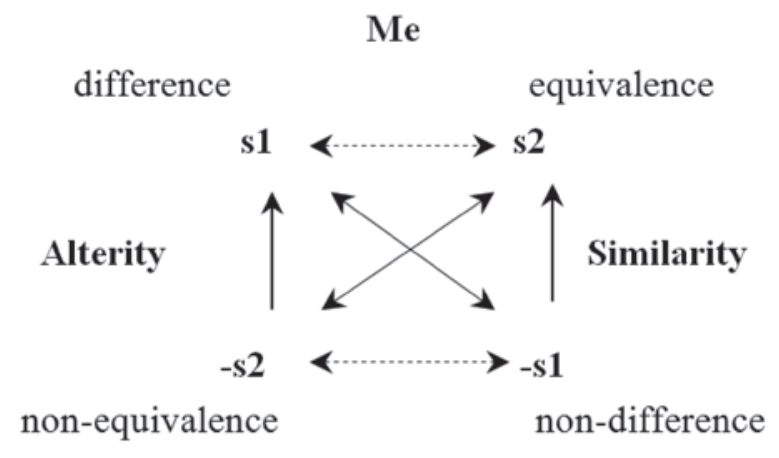

non-Me

Fig. 4: Semiotic square of translation

Following the heuristic operations and relations of the semiotic square, it is possible to now deploy, from the binary opposition difference/equivalence, the elementary structure of identity (Figure 4).

In the semiotic square, terms may be specified by each other, by their degree of generality and by their semic density. Therefore primitive term s1 may specify s2 if it has a greater semic density than s2. This means that s2 has a higher degree of generality than s1, which is more specific and therefore dominates the metaterm $\mathrm{S}$. The same may be applied to the terms -s1 and -s2: the term with a greater semic density and lower degree of generality will dominate the metaterm -S.

\subsection{Metaterm "Me"}

If the term "difference" has greater semic density and a lower degree of generality than the term "equivalence," it follows that "difference" specifies "equivalence" and the metaterm "Me" is realized as a difference in equivalence. "Me" differs in the equivalence.

If the term "equivalence" has a greater semic density and is less general than the term "difference," then "equivalence" specifies "difference" and the metaterm "Me" is realized as equivalence in difference. "Me" is equivalent in the difference.

If the two terms have the same semic density and same degree of generality, then "Me" is different and equivalent at the same time. The balance that 
is established between "difference" and "equivalence" is symptomatic of the resistance level of identity: if tolerance is high, "non-Me" is a highly participating element in the constitution of "Me." Conversely, if resistance is high, there is no participation of "non-Me" and "Me" is theoretically found to be in complete autarchy. These are two extreme situations, since there is always a degree of interaction between the two metaterms, and "non-Me" is always in a state of participation with "Me."

\subsection{Metaterm "non-Me"}

If the term "non-difference" has a higher semic density and is less general than the term "non-equivalence," it follows that "non-difference" specifies "nonequivalence." In the absence of categories of definition that might comprehend "non-Me," the metaterm remains an opaque entity, undefined, as something vaguely guessed and never fully grasped. In this case the metaterm is realized as "non-difference," so it is indefinite non-Me.

If the term "non-equivalence" has a greater semic density and is less general than the term "non-difference," then "non-equivalence" specifies "nondifference." In this case, the metaterm realizes as "non-equivalence" and emerges as a fundamentally dissimilar Other.

If the two contradictory terms specify each other, they have the same semic density and the same degree of generality, so then the metaterm "non-Me" is in balance between "non-difference" and "non-equivalence." "Non-Me" is the indefinite Other. The indefinite Other refers to the fact that "non-Me" is an other, i.e., not-equivalent to anything else - except to itself - and undefined because it appears as a vague premonition of something about which all that can be said is that it is an other.

At this stage, veridictory and identity modalities are clearly settled, so we will define the logic and semiotic conditions for the concept of translation as the synthesis of the identity and veridictory squares. Translation is the emergence of a "true," "illusory" or "secret" identity, and it exists at the point of tension between difference and equivalence, similarity and alterity, me and non-me. The result of the theoretical reasoning hitherto pursued leads to a visual representation of a new foundation: the semiotic square of translation (Figure 5).

In this semiotic square, translation is determined by the complex term "Me." Translation is defined as an object whose identity emerges as a synthesis of "difference" and "equivalence." Here, translation is also determined by the complex term "truth," since it is both "being in the difference" and "seeming equivalence.” In this descriptive model, the object of study also emerges through- 


\section{Semiotic square of translation}

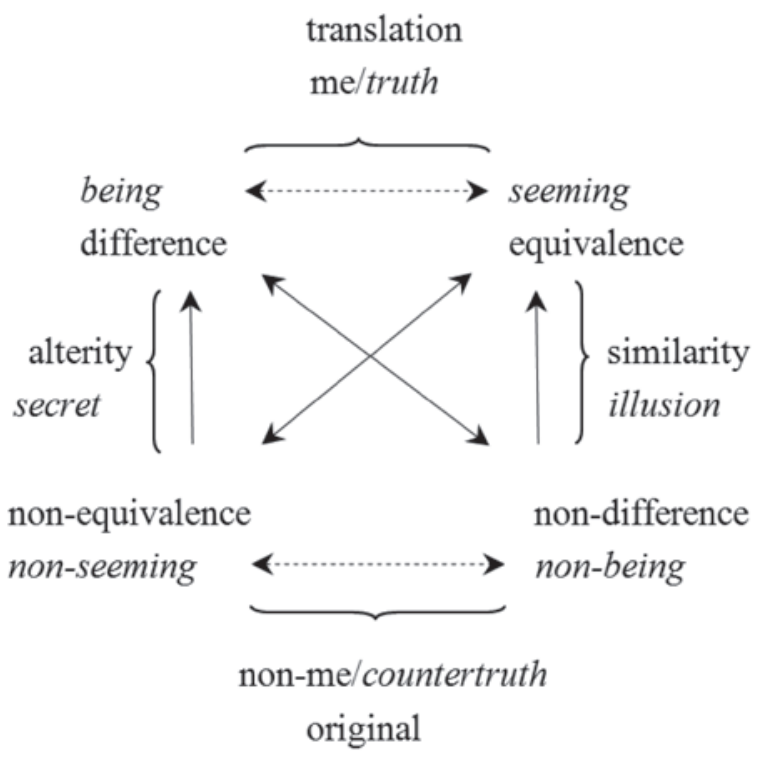

Fig. 5: Semiotic square of translation

out the operations of the square (opposition, negation and assertion) and it pertains alternatively to the complex metaterms "illusion" or "secret," "alterity" or "similarity."

The only change in the canonic semanticism of the positions of the veridiction square is the denomination of the opposite metaterm of "truth," which Greimas defines as "false." In our proposal, this term becomes "countertruth." In the semiotic square of translation, "truth" realized in the text translated by the translator refers to a specific language in a given historical moment, but it is not an absolute truth; rather, it is a relative truth related to a "countertruth," i.e., the truth of the original text.

The semiotic square encompasses a universe of virtual values that constitute the concept of translation. These virtualities must be realized either by the application to translated text (criticism of translation) or to a specific theoretical representation of translation (meta-theory).

In a meta-level analysis, the semiotic square of translation might explain ways and perspectives beyond the way in which certain theoretical proposals have viewed the concept of translation. Thus, we will now outline a semiotic analysis of some representative conceptions of translation. 


\subsection{The paradigm of difference}

In pre-scientific studies, translation is conceived of as a creative practice applied to literary or artistic texts in order to enrich style, innovate language and affirm one's culture. We are referring here to some views of translation found in Marcus Tullius Cicero (1993 [46 B.C.]), Martin Luther (2002 [1530]), Wilhelm von Humboldt (2002 [1816]), Johann W. Goethe 2002 [1819] and in one of the two methods of translation by Friedrich D. E. Schleiermacher 1997 [1813]. This list is not exhaustive, but is representative of some perspectives on translation.

According to these views, translation is a way in which to enhance language and, at the same time, to import gnoseological systems, i.e., contents related to a specific identity, the identity of non-Me, of a counterpart. Here, translation is a clear recognition of the otherness and distance of non-Me, and is realized as "difference in equivalence." This particular paradigm is described in the part of the semiotic square of translation in Figure 6.

The term "non-being | non-difference" - in the axis of contradictories motivates and generates the concept of translation. As the expression of the category "Me," translation is initially created with respect to the individual and col-

\section{Semiotic square of translation}

Paradigm of the difference

Translation

me/truth

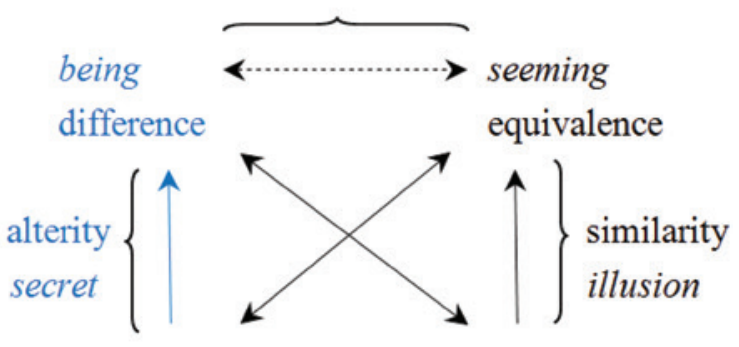

non-equivalence

non-seeming

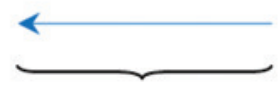

non-difference

non-being

\section{non-me/countertruth \\ original}

Fig. 6: Semiotic square of translation 
lective universe of "non-Me." In the semiotic square "non-Me is found in the same position as the original text. As indicated in the axis of specification of the identity square, when "non-difference" specifies "non-equivalence" the complex term "non-Me is indefinite ("non-difference" and "non-being"). Translation is realized as a movement that aims at grasping the entity "non-Me, but "non-Me is indefinite here; therefore, in order for it to be named and understood, it has first to be created by translation into the target culture and language, through individual (translators) and collective (society) modalities. In this case, translation is a highly productive event, for "non-Me" fully becomes part of "Me," in the only way it really can: by fostering innovation.

Following the series of operations and relations in the semiotic square, the contradictory term "non-being | non-difference" exists simultaneously with its opposite term "non-seeming | non-equivalence," which here represents because of a lower semic density - a passage allowing translation to be achieved in the first primitive term.

Translation is achieved as "being difference" and embodies a new identity. Translation is established through positive deixis selecting the metaterms "secret" and "alterity" in the semiotic square. Translation appears to be a simulacrum, which is not a simple imitation, but an instance that includes difference, abolishes resemblance and prevents any possibility of distinguishing between original and copy. In a Deleuzian way, here translation is to be seen as a true and lived reality of a representative domain (Deleuze 1994 [1968]: 69).

Operations that realize translation as a creative act are:

1. non-being $\mid$ non-difference $=>$ (2. non-seeming $\mid$ non-equivalence) $=>3$. being $\mid$ difference

\subsection{The paradigm of equivalence}

This was not the only way in which to conceive translation. As explained in the first part of this article, ideas on translation first emerged in binary positions. For instance, on one hand St. Jerome encouraged a free and creative translation of literary texts and on the other, he preached a literal translation of biblical texts. Similarly, Schleiermacher theorizes two methods of translating: the translator can translate in a free way if he/she aims to bring the author into the receiving culture and therefore obliterate any reference to foreign elements; or, conversely, a translator can decide to carry out a more literal translation, facilitating the reader's work as little as possible but bringing him/her closer to the cultural and linguistic differences of the author. According to this second method, 


\section{Semiotic square of translation \\ Paradigm of the equivalence}

\section{Translation}

me/truth

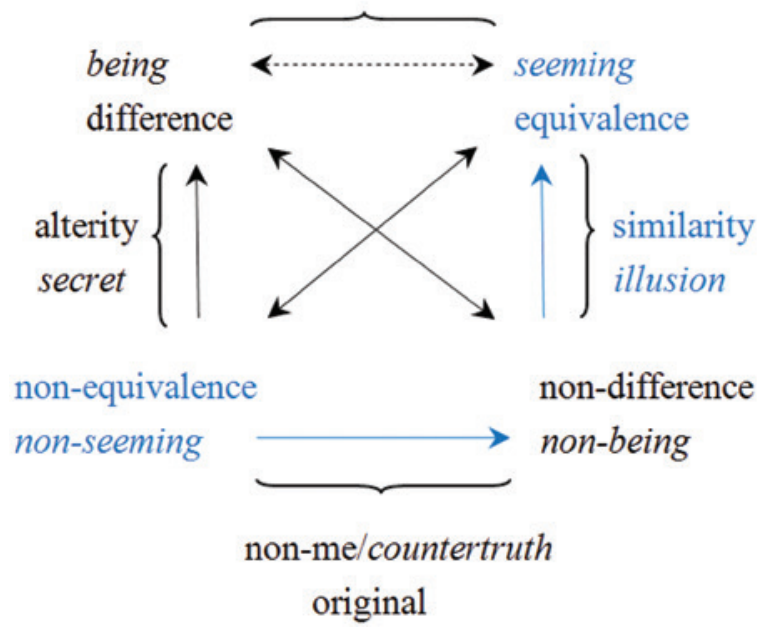

Fig. 7: Semiotic square of translation

translation is conceived as a generative operation that conveys all the formal and estranging aspects of the source text and culture, even at the cost of somehow compromising the process of understanding by producing an "opaque" translation text. This particular paradigm is described in part of the semiotic square of translation in Figure 7.

Translation is motivated by the term "non-seeming | non-equivalence" in the defining axis of the term "non-Me." Here, translation once again arises in the axis of the contradictories of the square identity. This confirms the fact that translation is an identity - "Me" - that always emerges in reference to "non-Me" by drawing on its categories. In particular, "non-Me" appears as "other" in its absolute otherness ("non-equivalence" and "non-seeming"). "Non-seeming" here refers to the fact that "other" is not a straightforward entity, but rather, a highly symbolic and hidden one - as in the translation of biblical texts, for instance which only few hermeneutists can access.

The term "non-being | non-difference" emerges as the simultaneous opposite to "non-seeming | non-equivalence," which then leads, through the operation of assertion, to the primitive term, "seeming | equivalence." 
Once the axis of the contradictories is defined as the generator axis, the translation is realized through the primitive term "seeming | equivalence." Translation here is also a creation of a new identity that appears to be equivalent and is achieved through the negative deixis of the metaterms "illusion" and "similarity." These two terms refer to the fact that translation is an illusionary similar event. Translation is a copy and image derived from an original model - the idea that originated it. Once again, this involves the concept of the Deleuzian "copy": the model has higher identity and originality, while the copy is judged on the basis of its degree of similarity, "since copies are selected, justified and saved in the name of the identity of the model and owing to their internal resemblance to this ideal model" (Deleuze 1994 [1968]: 127).

Operations that realize translation as a reconstructive act are:

1. non-seeming $\mid$ non-equivalence $=>$ (2. non-being $\mid$ non-difference) $=>$ 3. seeming $\mid$ equivalence.

In the two instances above, the semiotic square provides a general and virtual description of the concept of translation. With the establishment and enlargement of the field of translation studies, these two approaches have subsequently evolved into a more complex and less dichotomous way of conceiving translation.

\subsection{The paradigm of paradox}

According to current approaches, translation appeals to the terms in the semiotic square in a way different from the patterns so far described. In particular, it is no longer motivated by a single term in the contradictories axis, but derives from direct relation to its opposite, the metaterm "Original" and "non-Me. Furthermore, translation is carried out as an entity that both "is" (being) and "seems" (seeming) "true," it is realized more properly as a "secret" and "illusory" entity.

In the semiotic square, this new approach to translation refers to the conceptual paradigm of translation as paradox, as "the equivalence in the difference." The original, the "non-Me," the "indefinable other" is the generative trigger of translation. The result is "Me," a translational truth, an entity realized as an apparent equivalence and actual difference enclosed in a different verbal body.

This particular paradigm is described in the semiotic square of translation in Figure 8.

This new conceptualization of translation is embedded in the semiotic square as a paradoxical value. 


\section{Semiotic square of translation}

Paradigm of the paradox

Translation

me/truth

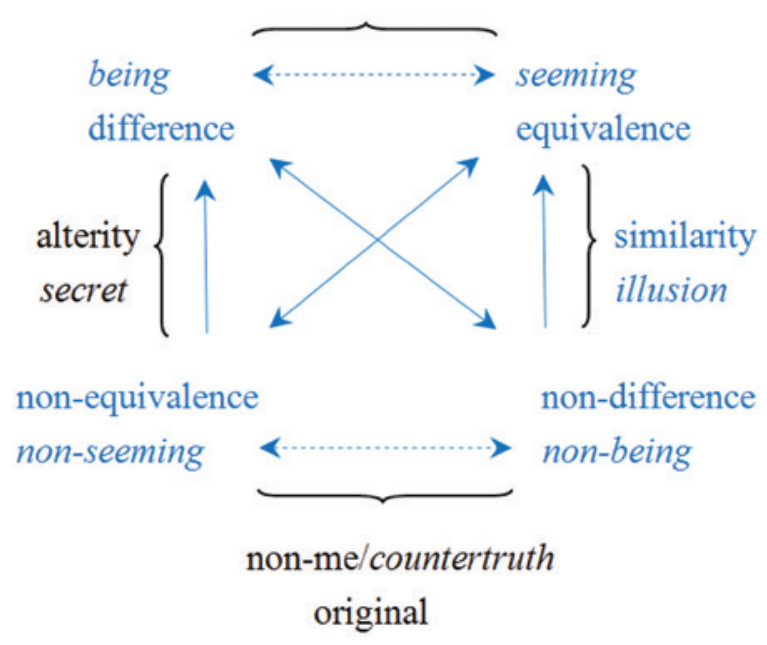

Fig. 8: Semiotic square of translation

If translation is to be conceived as a heterogeneous and complex object of study - as per the contemporary theories - it must find its genesis in a semiotic metaterm that is also complex and composite. Consequently, translation is not motivated by a single term in the contradictories axis - as is the case of the above paradigms - but by the metaterm "non-Me | Original." The two contradictories terms specify each in equilibrium, since they have the same semic density and an equal degree of generality. In the veridictory square, this position corresponds to "countertruth," a complex metaterm in which "non-seeming" and "non-being," both specify each other. By the same token, in the square of identity the metaterm "non-Me" is in balance between "non-equivalence" and "non-difference." Translation emerges from "non-Me," i.e., the indefinite Other, the "countertruth" set in the Original. "Non-Me," the Original, is indefinite because its truth is only realized when the translation is realized and appears in the receiving culture and language. The definition of the meaning of "non-Me" as "Other" appears only in the translation. In other words, the meaning of the Original is never given once and for all, its "being" and "seeming" true is given through the translational verbal body. 
The axis of the contradictories is again the motivational and generative point of the concept of translation, since the metaterm "Original" is in relation to the metaterm "Translation" through negative and positive deixis, i.e., through the assertion of the contradictory terms "non-seeming | non-equivalence" and "nonbeing | non-difference" into the axis of primitive opposites "being | difference" and "seeming | equivalence." Translation permanently subsumes opposite terms, and this explains why it is fully realized as a paradoxical semiotic object. Translation is an entity with its own identity ("Me-translation") and this identity is manifestly equivalent and immanently different. This is arguably the distinctive condition of the concept of translation.

Furthermore, translation simultaneously calls for the metaterms "secret" and "illusion." These categories make the fact that translation is a doubly masked entity explicit: it is subjectively masked, since it is secret in order to seem true, and objectively masked because it must create the illusion of being objectively real in order to be accepted as true.

Operations of realization of translation as a paradox are:

1) non-seeming | non-equivalence and non-being | non-difference $=>2$ ) being | difference and seeming | equivalence.

This representation refers to modern theoretical approaches to translation and aims at providing a more comprehensive and accurate perspective of its complexity. Several scholars accept the paradoxical condition that characterizes the concept of translation and the fact that it implies a coexistence of difference and equivalence. In particular, Theo Hermans (2002) first raised the question of the paradoxes and aporias of translation. Among the more paradoxical elements, there is the concealment of the translator's presence - the alleged erasure of his voice is seen as a paradoxical element since its traces always remain in the translated text. Moreover, translation never appears to be a neutral, transparent and innocent act, because with his/her personal cultural and linguistic background, the translator selects and imports the elements of the original in the receiving community, transforming them into something perfectly understandable for the members of that community; therefore, the translated text cannot be equivalent, its equivalence being purely declared (Hermans 2002: 11).

\section{Conclusion}

On the basis of the application of the semiotic square here described, we could affirm that, from a methodological point of view, this device can be helpfully 
adopted to semiotically examine the idea of "translation" in past reflections or studies. According to this perspective, the three paradigms of translation are declinations of the semiotic square, seen as a meta-theoretical model describing theories on the concept of translation.

Nevertheless, according to the Generative Trajectory of Meaning, research should be directed at extending the categories of the semiotic square into human reality, into the anthropological dimension of translation. At this level of analysis, translation should no more be seen as a theoretical concept than a human practice. The conversion of translation paradigms into human reality provides the virtual dimension of the semiotic square with a realization into socio-cultural reality. This new theoretical perspective calls for an in-depth study of generative grammar, i.e., a determination of the actants, narrative programs and semiotic modalities that characterize semiotic translation as a social and cultural practice.

Finally, on a third level of analysis, research should focus on the textual manifestation of the translated text and the specificities of the enunciative framework of translation. The semiotic square of translation offers the possibility of establishing a link between the square's categories and the linguistic manifestation of translated texts. It is indeed possible that translation choices corroborate the conceptual paradigms described in the square. The description of translation as a paradoxical event that emerges as an illusory and secret entity points to the fact that, on the level of linguistic manifestation, a translated text is founded on the illusory concealment of the enunciative marks pertaining to translators. In its manifestation, a translated text not only interprets the meaning of the original text but also offers clues to the interpretative strategies used. In other words, the semiotic square allows us to comprehend and systematize the textual marker the "evaluative" and thymic filters adopted by the translator. This stage of analysis naturally leads us to consider the discursive structures in the Generative Trajectory of Meaning. The semiotic definition of enouncement provides a suitable methodology to investigate enunciative mechanisms in translation, and to identify ways in which the translator's voice clearly emerges in the translated text. These three levels of analysis - meta-theoretical, phenomenological and textual - represent just as many corresponding research-based spin-offs.

\section{References}

Ballard, Michel. 2007. De Cicéron à Benjamin. Traducteurs, traductions, réflexions, 3rd edn. Lille: Presses Universitaires du Septentrion.

Berman, Antoin. 1989. La traduction et ses discours. Meta 34(4). 672-679. 
Chesterman, Andrew. 1997. Memes of translation: The spread of ideas in translation theory. Amsterdam: Benjamins.

Chesterman, Andrew. 2006. Vers une traductologie poppérienne. In Michel Ballard (ed.), Qu'est-ce-que la traductologie?, 171-178. Arras: Artois Presses Université.

Chesterman, Andrew. 2008. The status of interpretive hypothesis. In Gyde Hansen, Andrew Chesterman \& Heidrun Gerzymisch-Arbogast (eds.), Efforts and models in interpreting and translation research, 49-61. Amsterdam \& Philadelphia: John Benjamins.

Cicero, Marcus Tullius. 1993 [46 B.C.]. De optimo genere oratorum. In Siri Nergaard (ed.), La teoria della traduzione nella storia, 51-62. 1993. Milan: Bompiani.

Cosculluela, Cécile. 1996. Traductologie et sémiotique peircienne: l'émergence d'une interdisciplinarité, Bordeaux: Université Michel de Montaigne Bordeaux III dissertation.

Cosculluela, Cécile. 2003. Semiotics and translation studies: An emerging interdisciplinarity. Semiotica 145(1/4). 105-137.

Deleuze, Gilles. 1994 [1968]. Difference and repetition, Paul Patton (trans.). New York: Columbia University Press.

Derrida. Jacques. 1967. L'écriture et la différence. Paris: Seuil.

Folkart, Barbara. 1984. A thing-bound approach to the practice and teaching of technical translation. Meta 29(3). 229-246.

Goethe, Johann W. 2002 [1819]. Note e saggi sul Divan Orientale-Occidentale. In Siri Nergaard (ed.), La teoria della traduzione nella storia, 121-125. Milan: Bompiani.

Gorlée, Dinda. 1989. Wittengstein, translation, and semiotics. Target 1(1). 69-94.

Gorlée, Dinda. 1994. Semiotics and the problem of translation: With special reference to the semiotics of Charles S. Peirce. Amsterdam \& Atlanta: Rodopi.

Gorlée, Dinda. 2004. On translating signs: Exploring text and semiotranslation. Amsterdam \& New York: Rodopi.

Gorlée, Dinda. 2010. The black box of translation: A glassy essence. Semiotica 180(1/4). 79-114.

Greimas, Algirdas J. 1970. Du sens: essais sémiotiques. Seuil: Paris.

Greimas, Algirdas J. 1983. Du sens 2: essais sémiotiques. Seuil: Paris.

Greimas, Algirdas J. 1987. On meaning: Selected writings in semiotic theory, Paul Perron \& Frank H. Collins (trans.). Minneapolis: University of Minnesota Press.

Greimas, Algirdas J. 1990. Narrative semiotics and cognitive discourses, Paul Perron \& Frank H. Collins (trans.). London: Pinter.

Greimas Algirdas J. \& Joseph Courtés. 1982 [1979]. Semiotics and language: An analytical dictionary, Larry Christ, Daniel Patte, James Lee, Edward McMahon II, Gary Phillips \& Michael Rengstorf (trans.). Bloomington, IN: Indiana University Press.

Greimas Algirdas J. \& Joseph Courtés. 1986. Sémiotique: dictionnaire raisonne de la théorie du langage, vol. 2. Paris: Hachette.

Hartama-Heinonen, Ritva. 2008. Abductive translation studies: The art of marshalling signs (Acta Semiotica Fennica 28). Imatra: International Semiotics Institute.

Hermans, Théo. 2002. Paradoxes and aporias in translation and translation studies. In Alessandra Riccardi (ed.), Translation studies: Perspectives on an emerging discipline, 10-23. Cambridge: Cambridge University Press.

Hewson, Lance. 2012. Équivalence, leurre, divergence. In Camille Fort \& Florence LautelRibstein (eds.), Des mots aux actes $N^{\circ}$ 3. Jean-René Ladmiral, une œuvre en mouvement, 257-270. Perros-Guirec: Anagrammes. 
Holmes, James. S. 2000 [1972]. The name and nature of the translation studies.

In Lawrence Venuti (ed.), The translation studies reader, 172-185. London \& New York: Routledge.

Humboldt, Wilhelm von. 2002 [1816]. Einleitung zur Agamemnon - Übersetzung. In Siri Nergaard (ed.), La teoria della traduzione nella storia, 125-144. Milan: Bompiani.

Jakobson, Roman. 1960. Closing statements: Linguistics and poetics. In T. A. Sebeok (ed.), Style in language, 350-377. Cambridge: MIT Press.

Jakobson, Roman. 2004 [1959]. On linguistic aspects of translation. In Lawrence Venuti (ed.), The translation studies reader, 2nd edn., 138-143. London \& New York: Routledge.

Jerome, St. 1976 [390]. To Pammachius: On the best method of translating (Letter 57), L. G. Kelly (trans.). Ottawa: University of Ottawa, School of Translators and Interpreters.

Ladmiral, Jean-René. 2003. Épistémologie de la traduction. In Salah Mejri, Taïeb Baccouche, André Class \& Gaston Gross (eds.), Traduire la langue, traduire la culture: Rencontres linguistiques, 147-168. Paris: Maisonneuve et Larose.

Luther, Martin. 2002 [1530]. Epistola sull'arte del tradurre e sulla intercession dei santi. In Siri Nergaard (ed.), La teoria della traduzione nella storia, 99-120. Milan: Bompiani. Nergaard, Siri. 2001. Semiotica interpretativa e traduzione. Athanor 12(4). 57-77.

Peirce, Charles S. 1931-1966. The collected papers of Charles S. Peirce, 8 vols., C. Hartshorne, P. Weiss \& A. W. Burks (eds.). Cambridge: Harvard University Press. [Reference to Peirce's papers will be designated $C P$ followed by volume and paragraph number.]

Petrilli Susan. 2000. La metempsicosi del testo e la corsa della tartaruga. Borges e la traduzione. Athanor 11(3). 219-230.

Petrilli Susan. 2001. Il carattere intersemiotico del tradurre. Athanor 12(4). 9-19.

Petrilli, Susan. 2002. Text metempsychosis and the racing tortoise: Borges and translation. Semiotica 140(1/4). 153-167.

Reiss, Katharina. 1971. Möglichkeiten und Grenzen der Übersetzungskritik: Kategorien und Kriterien für eine sachgerechte Beurteilung von Übersetzungen. Munich: M. Hueber.

Reiss, Katharina. 2000. Type, kind, and individuality of text: Decision making in translation. In Lawrence Venuti (ed.), The translation studies reader, 160-171. London \& New York: Routledge.

Schleiermacher, Friedrich D. E. 1997 [1813]. Über die verschiedenen Methoden des Üebersetzen. In André Lefevere (ed.), Translating literature: The German tradition. From Luther to rosenzweig, 66-89. Assen \& Amsterdam: Van gorcum.

Stecconi, Ubaldo. 2004. Interpretive semiotics and translation theory: The semiotic conditions to translation. Semiotica 150(1/4). 471-489.

Stecconi, Ubaldo. 2007. Five reasons why semiotics is good for translation studies. In Y. Gambier, M. Schlesinger \& R. Stolze (eds.), Doubts and directions in translation studies: Selected contributions from the EST Congress, 15-25. Amsterdam: John Benjamins.

Stecconi, Ubaldo. 2008. Revisiting the classics: A landmark in the semiotics of translation. Review of Dinda L. Gorlee. On Translating Signs: Exploring Text and Semio-translation. Target 17(2). 381-386.

Venuti, Lawrence. 2002. The difference that translation makes. In A. Riccardi (ed.), Translation studies: on an emerging discipline, 214-241. Cambridge: Cambridge University Press. 


\section{Bionote}

Rovena Troqe (b. 1981) holds a PhD from University of Geneva <rovena.troqe@ unige.ch>. Her research interests include translation studies, Greimassian semiotics, epistemology and methodology of translation, and self-translation. Her publications include “La questione dell'espressività in traduttologia” (2011); and "Traduttologia e semiotica generativa: per un nuovo approccio interdisciplinare” (2014). 